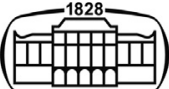

AKADÉMIAI KIADÓ

\title{
Study of stability analysis of power system with increasing wind power
}

\author{
MOHANAD ABDULHAMID ${ }^{1 *}$ () and KOECH BENARD ${ }^{2}$
}

\section{International Review of Applied Sciences and Engineering}

$11(2020) 1,1-3$

DOI:

$10.1556 / 1848.2020 .00001$

(C) 2020 The Authors

ORIGINAL RESEARCH PAPER

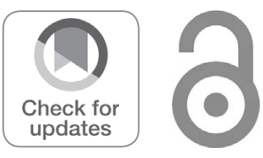

*Corresponding author. E-mail: moh1hamid@yahoo.com, researcher12018@yahoo.com

\author{
1 AL-Hikma University, Iraq \\ ${ }^{2}$ University of Nairobi, Kenya
}

Received: January 21, 2019 - Accepted: March 20, 2019

Published online: April 18, 2020

\section{ABSTRACT}

The use of energy in the world today is increasing with increase in population. The cost and availability of energy significantly impacts our quality of life, the health of national economies and the stability of our environment. The rapid depletion of fossil fuel resources on a worldwide basis has necessitated an urgent search for alternative energy sources to cater to the present day demands. In recent years there has been a significant global commitment to develop clean and alternative sources of energy such as solar and wind. Wind energy technology has been the fastest growing energy source because it is fairly distributed around the world and readily available for use. However, more penetration of wind energy into existing power networks has some impacts on the stability of the power system. Therefore, this paper studies and analyzes the stability of a power system with increasing wind penetration. The paper presents some analyses of a power system and the dynamic behavior which identify the issues that limit the large-scale integration of wind generators in a power system.

\section{KEYWORDS}

stability analysis, power system, wind power

\section{INTRODUCTION}

Wind energy is one of the major sources of renewable energy with a remarkable contribution to the installed capacity of electrical power systems. Wind power has been used in ancient times for applications such as: pumping water, grinding mills and in propelling boats. Its contribution in the electricity supply began in the mid 1980s and is now firmly established as one of the major technologies of electricity generation in the world. It is one of the fastest growing electricity generating technologies in the world and features in both developed and developing countries.

Rapid expansion of wind power has been driven by a combination of its environmental benefits, various state and federal policies and incentives, and improving cost-competitiveness with other generating technologies.

The wind turbine generators in a wind farm are distributed within the farm, but the total output of the farm normally connects to the bulk power system at a single substation, in a fashion similar to conventional central-station generation. Integration of large quantities of wind power has, however, presented some challenges such as absorption of reactive power from the grid during faults, which affects system stability in weak power grids.

Power generation using wind differs in several respects from conventional sources of energy such as hydro and thermal, the major difference being that wind generators are usually based on induction generator technologies instead of the conventional synchronous generators. The induction generators are known to consume reactive power (like in induction motors) during system contingency, which in turn affect the stability of a power system.

The issue of the study dependent on the stability in a power system is during and after a fault is introduced to a system. Besides, if and just if the fault does not achieve any 
supportable change in power the machine must return to its unique state. In the event that imbalanced interest makes change in burden or system/generation condition, new working state is required. In this way, it very well may be said that in all matters inter-connected synchronous machines should maintain synchronism, for example they need to work at the same velocity in parallel. The system unsettling influence makes transients of oscillatory nature, however, on the off chance that nature of system is stable, these motions will be soak to new stable condition. Some related researches can be found in literature [1-6].

\section{METHODOLOGY}

\subsection{Power system modeling using MATLAB Simulink}

A micro-grid is modeled by connecting distributed generators near the load together with main grid as shown in Fig. 1.

Generator DG3 is introduced and integrated into the micro-grid. The generator DG3 represents a wind farm. The proposed wind farm is aggregated to an equivalent generator producing $300 \mathrm{MW}$. The wind power generator is modeled using MATLAB Simulink and integrated to the micro-grid.

\subsection{Excitation control system}

The automatic voltage regulator (AVR) and the power system stabilizer comprise the excitation control system. They are modeled and included in the system. Further simulations were carried out so as to ascertain their effect.

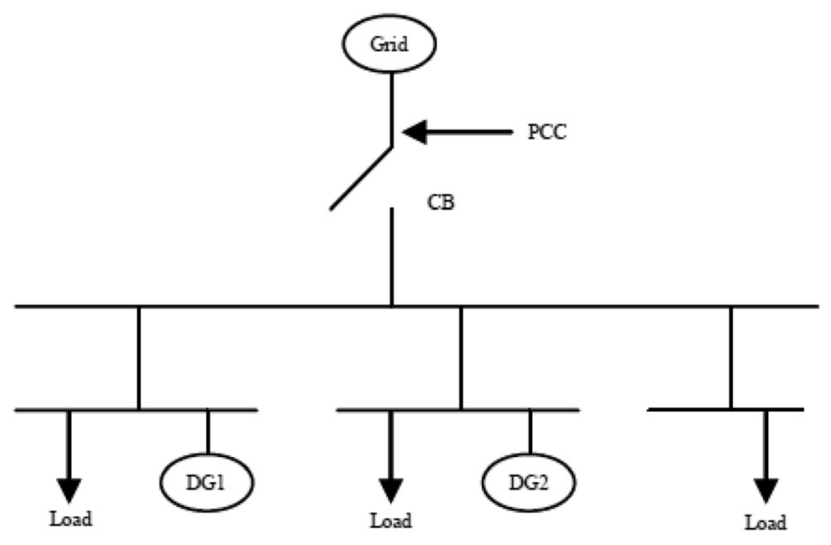

Figure 1. Micro-grid system

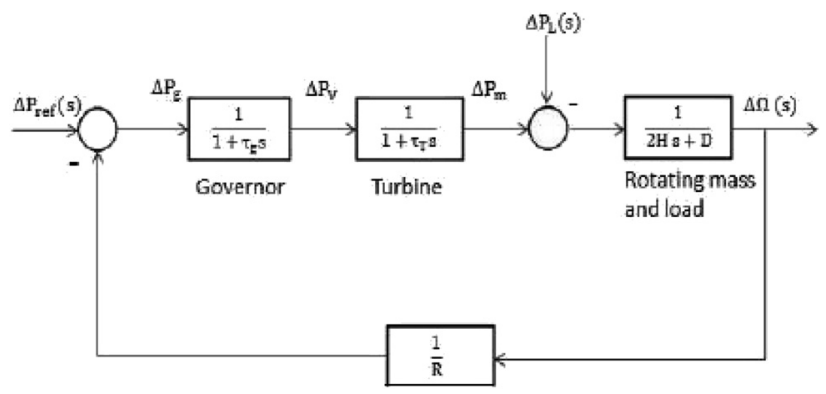

Figure 2. Model of load frequency control

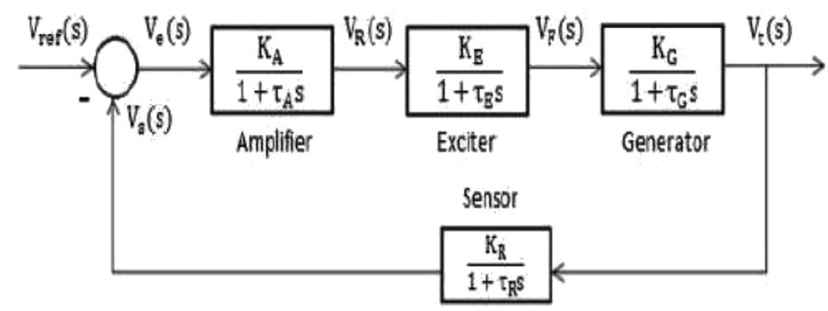

Figure 3. Generator block diagram with AVR

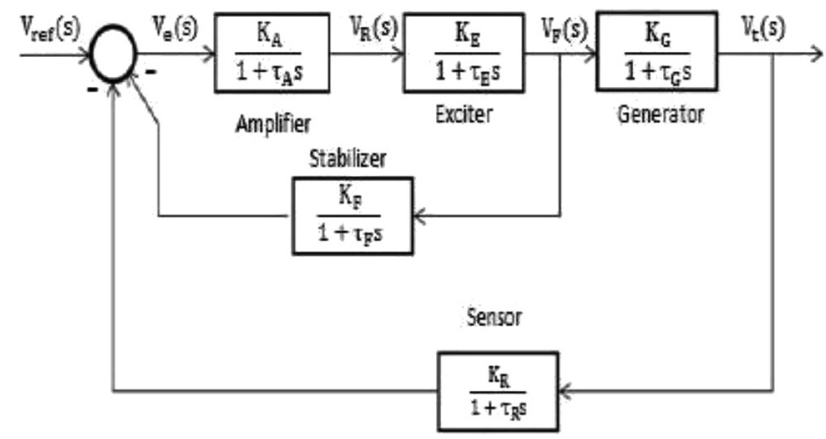

Figure 4. Generator block diagram with AVR and rate feedback stabilizer

\subsection{Simulation block diagrams}

The load frequency control (LFC) model of an isolated power system is modeled as shown in Fig. 2.

Figure 3 shows generator diagram with AVR.

Figure 4 shows generator diagram with AVR and feedback stabilizer.

An assumption is made that wind speed is constant, all the wind turbines are exposed to the same wind speed and turbulence level. These assumptions are made so that the wind turbines could be considered to produce their maximum rated power. A short circuit fault is introduced on

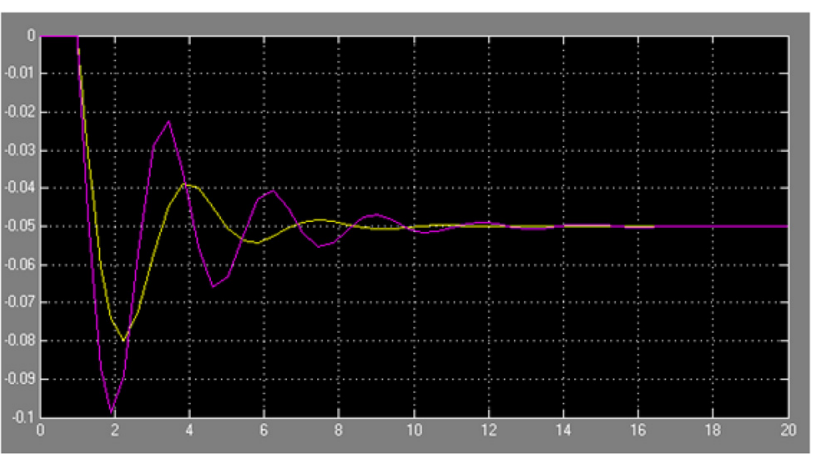

Observations

$\mathrm{Y}$ axis- frequency deviation

$\mathrm{X}$ axis-time( seconds)

With wind

Without wind

Figure 5. Steady state response of LFC model 


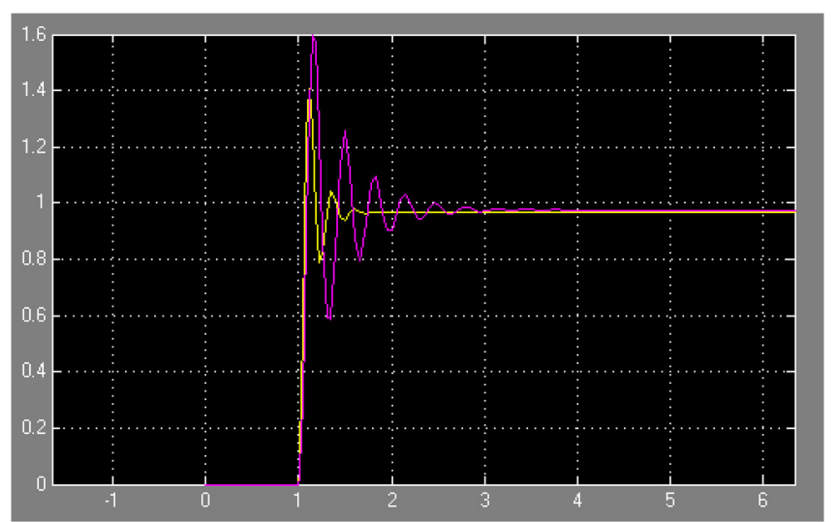

Observations

$\mathrm{Y}$ axis- $\mathrm{p} . \mathrm{u}$ terminal voltage

$\mathrm{X}$ axis-time( seconds)

With wind

Without wind

Figure 6. Transient response with AVR only

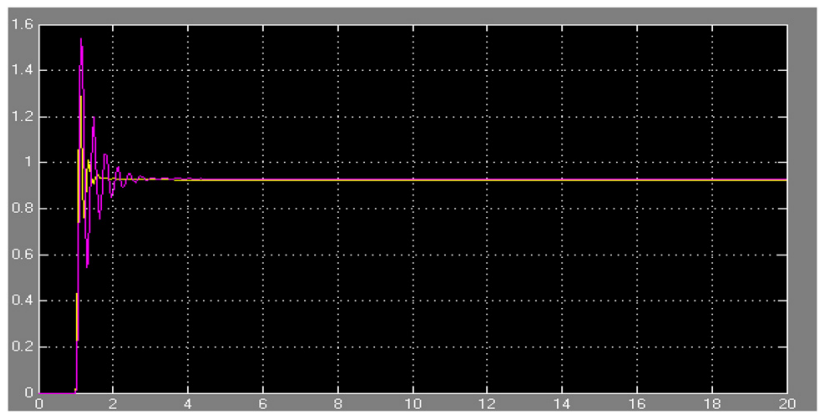

Observations

Y axis- p.u terminal voltage

$\mathrm{X}$ axis-time( seconds)

With wind

Without wind

Figure 7. Transient response with AVR and rate feedback stabilizer

the bus connecting the micro-grid to the main grid. It is introduced after $1 \mathrm{~s}$ and cleared after $1.01 \mathrm{~s}$ by tripping the line. The behavior of the generators is observed and analyzed after the fault.

\section{SIMULATION RESULTS}

The simulations are carried out with and without the wind farm for the different models. The LFC of the isolated power system is simulated. The steady state response of LFC model with and without the wind farm is shown in Fig. 5.

Figure 6 shows the transient response of the power system with AVR only.

Figure 7 shows transient response of the power system with AVR and rate feedback stabilizer.

From the results it can be seen that with the inclusion of wind power, the terminal voltage takes a longer time to settle after the fault. Also, the frequency deviation takes a longer time to settle when the wind power is included. It is also noted that the damping is better when wind power is not included.

\section{CONCLUSION AND DISCUSSION}

In this paper, stability of a power system was analyzed. The performance of the system without wind power was studied first and then was compared with the case when wind power is present. It was observed after considering the settling time of different parameters after a system fault that the operation of the system can be enhanced with inclusion of the excitation controllers in the model. This inclusion of the excitation control system is necessary when considering integrating this large wind farm into the system.

\section{REFERENCES}

[1] J. Slootweg and W. Kling, "Modelling and analysing impacts of wind power on transient stability of power systems," Wind Eng., vol. 26, no. 1, pp. 3-20, 2002.

[2] R. Melício, V. Mendes, and J. Catalão, "Computer simulation of wind power systems: power electronics and transient stability analysis," in Int. Conf. Power Sys. Trans., Kyoto, Japan. 2009.

[3] B. Sun, H. Zhengyou, Y. Jia, and K. Liao, "Small-signal stability analysis of wind Power system based on DFIG," Energy Power Eng., vol. 5, pp. 418-422, 2013.

[4] M. Deshmukh and C. Moorthy, "Review on stability analysis of grid connected wind power generating system," Int. J. Electr. Electron. Eng. Res., vol. 3, no. 1, pp. 1-33, 2013.

[5] H. Rui, H. Weihao, and C. Zhe, "Review of power system stability with high wind power penetration," Proc. 41th Annu. Conf. IEEE Indus. Electron. Soc., Yokohama, Japan, IEEE. 2015.

[6] F. Islam and A. Lallu, "Impact of wind generators in power system stability.” WSEAS Trans. Power Syst., vol. 13, pp. 235-248, 2018. 